\title{
Diferentes graus de moagem em dietas para cães
}

\author{
Different milling in diets for dogs
}

\section{Karini Portela HilckoI Ananda Portella Félix ${ }^{I}$ Simone Gisele de OliveiraII Marcelino Bortolo ${ }^{\mathrm{III}}$ Alex Maiorka ${ }^{\mathrm{II}}{ }^{*}$ Cleusa Bernardete Marcon de Brito ${ }^{\mathrm{I}}$ Pâmela Fernandes Alves ${ }^{\mathrm{IV}}$}

\section{RESUMO}

As características físicas da dieta, dentre elas a granulometria, exercem importante papel no aproveitamento da dieta pelos animais. Desse modo, o presente estudo teve como objetivo avaliar os efeitos da granulometria da dieta sobre a digestibilidade e a metabolizabilidade da energia de rações secas extrusadas para cães. Oito cães adultos da raça Beagle foram distribuidos em delineamento quadrado latino duplo (4 $x 4$ ), totalizando oito repetições no tempo. Os ingredientes foram moídos em peneiras de 0,8;1,0;1,2 e $1,5 \mathrm{~mm}$, resultando em rações com diâmetro geométrico médio (DGM) de 468, 476, 499 e 588um, respectivamente. Cada periodo experimental foi composto por cinco dias para adaptação às dietas e cinco dias de coleta total de fezes. As análises de correlação e regressão linear demonstraram relação negativa entre o DGM e os coeficientes de digestibilidade aparente (CDA) da proteina bruta $(y=94,82-42,05 x)$, o extrato etéreo em hidrólise ácida $(y=86,57-35,02 x)$, os extrativos não nitrogenados $(y=102,48-48,42 x)$ e a energia metabolizável $(y=3597,56-1697,00 x)$. Não foi observado efeito do DGM sobre o consumo de matéria seca e o CDA da matéria seca. Houve piora na qualidade das fezes à medida que o DGM das dietas aumentou. Portanto, a menor granulometria da ração está relacionada ao melhor aproveitamento dos nutrientes e à energia da dieta e à produção de fezes de melhor qualidade pelos cães.

Palavras-chave: digestibilidade, granulometria, nutrição de cães.

\section{ABSTRACT}

The physical characteristics of the diet, including particle size, exert important role in animals diet usage. So, the current study aimed to evaluate the effect of diet granulometry on nutrients digestibility and metabolizability of energy in dogs. Eight adult Beagle dogs were distributed in a double latin square design (4 $x 4$ ), totaling eight replicates in time. The ingredients of diets were ground in sieves of: $0.8,1.0$, 1.2 and $1.5 \mathrm{~mm}$, and the diets particle size were expressed as

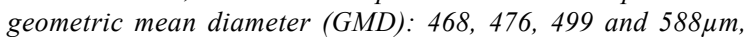
respectively. Each experimental period was composed by five days for diet adaptation and five days of total feces collection. The correlation and regression analyses showed a negative relationship between GMD and coefficient of apparent digestibility (CAD) of crude protein $(y=94.82-42.05 x)$, acid ether extract $(y=86.57-35.02 x)$, nitrogen free-extract $(y=102.48-48.42 x)$ and metabolizable energy $(y=3597.56$ 1697.00x). It was not observed effect of GMD on dry matter intake and dry matter CAD. There was lower fecal score with increasing GMD of foods. Therefore, the lowest particle size of food resulted in better use of nutrients and diet energy and production of drier feces by dogs.

Key words: digestibility, particle size, dogs nutrition.

\section{INTRODUÇÃO}

A literatura apresenta vários artigos acerca da avaliação da composição nutricional de alimentos para cães. Entretanto, ainda há escassez de informações a respeito do efeito das características físicas da dieta sobre o aproveitamento dos nutrientes (SÁ-FORTES, 2005; CARCIOFI et al., 2006).

'Programa de Pós-graduação em Ciências Veterinárias, Universidade Federal do Paraná (UFPR), Curitiba, PR, Brasil.

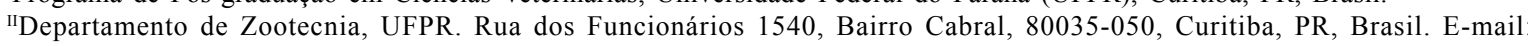
amaiorka@ufpr.br.*Autor para correspondência.

IIIPrograma de Pós-graduação em Zootecnia, Universidade Estadual de Maringá (UEM), Maringá, PR, Brasil.

${ }^{\mathrm{IV}}$ Curitiba, PR, Brasil. 
O tamanho de partículas dos ingredientes que compõem a dieta pode ter reflexos significativos no aproveitamento dos alimentos pelos animais. Menores granulometrias permitem maior gelatinização do amido durante a extrusão e maior ação das enzimas digestivas sobre os nutrientes, melhorando a digestibilidade. Por outro lado, pode resultar em aumento na taxa de passagem do alimento pelo trato digestório, reduzindo o contato das enzimas digestivas com os nutrientes e sua absorção, comprometendo o aproveitamento dos nutrientes pelo organismo.

A indústria adota a prática da moagem fina (0,6-0,8mm), principalmente para alimentos dos tipos prêmio e superprêmio (ANFALPET, 2008), de forma a garantir acentuada redução no tamanho das partículas, melhorando a homogeneização e a digestibilidade dos ingredientes, o grau de gelatinização do amido, a qualidade do extrusado e o aspecto visual da ração.

A eficiência do processo de produção dos alimentos está diretamente relacionada à moagem dos ingredientes, já que o moinho, depois da extrusora, é o equipamento que mais consome energia e tempo na fábrica de ração. Embora ainda apresentem resultados contraditórios, vários trabalhos com aves e suínos apontam benefícios concedidos por determinados níveis granulométricos (HEALY et al., 1994; HAMILTON \& PROUDFOOT, 1995; DAHLKE et al., 2001). Entretanto, há escassez de informação na literatura sobre o melhor grau de moagem para cães.

O conhecimento da influência do grau de moagem é de grande valia para a indústria de alimentos para cães, pois permitirá melhor fundamentação do processo de seus produtos e das formulações dos alimentos, tornando possível obter ganhos em energia metabolizável, digestibilidade e qualidade das fezes (BAZOLLI, 2007).

Dessa forma, o presente estudo teve como objetivo avaliar o efeito de diferentes graus de moagem dos ingredientes de alimentos secos extrusados para cães adultos sobre a digestibilidade dos nutrientes, metabolizabilidade da energia e qualidade das fezes.

\section{MATERIAL E MÉTODOS}

O experimento foi desenvolvido no Laboratório de Estudos de Nutrição Canina LENUCAN - do Departamento de Zootecnia da Universidade Federal do Paraná (UFPR). Foram formuladas dietas com os mesmos ingredientes, diferindo apenas quanto à sua granulometria (Tabela 1). A composição nutricional das dietas experimentais superou as recomendações da AAFCO (2004) para cães adultos em manutenção (Tabela 1).
Para a fabricação dos alimentos, os ingredientes foram moídos separadamente em moinho de martelos, com peneiras de 0,8; 1,0; 1,2 e 1,5mm, sendo as dietas expressas como diâmetro geométrico médio (DGM): 468, 476, 499 e $588 \mu \mathrm{m}$, respectivamente. Uma amostra foi retirada de cada dieta antes da extrusão para determinação do DGM, o qual foi obtido por meio de um conjunto de peneiras de 1,4mm; 1,2mm; 1,0mm; $0,7 \mathrm{~mm} ; 0,5 \mathrm{~mm} ; 0,35 \mathrm{~mm} ; 0,125 \mathrm{~mm}$ e fundo, sendo os valores calculados pelo programa Gransuave, segundo os procedimentos descritos por ZANOTTO \& BELLAVER (1996). Após moagem, os ingredientes foram misturados e extrusados.

Foram utilizados oito cães adultos da raça Beagle, machos e fêmeas, não castrados, sadios e vermifugados, com peso médio de $10 \mathrm{~kg}$ e idade média de dois anos. Os animais foram alojados individualmente em gaiolas metabólicas $(0,7$ x 0,6 x $0,5 \mathrm{~m})$. Os cães foram distribuídos em delineamento quadrado latino duplo (4 x 4) (períodos x tratamentos), totalizando oito repetições por tratamento.

Cada período experimental constou de 10 dias, sendo cinco dias para adaptação às condições experimentais e dietas e cinco para coleta de dados. $\mathrm{O}$

Tabela 1 - Ingredientes e composição química das dietas experimentais.

\begin{tabular}{|c|c|c|c|c|}
\hline Ingredientes & \multicolumn{4}{|c|}{$\%$} \\
\hline Milho & \multicolumn{4}{|c|}{35,00} \\
\hline Farinha de víscera de frango & \multicolumn{4}{|c|}{16,00} \\
\hline Quirera de arroz & \multicolumn{4}{|c|}{13,43} \\
\hline Farinha de carne 45 & \multicolumn{4}{|c|}{10,52} \\
\hline Farinha de trigo & \multicolumn{4}{|c|}{10,00} \\
\hline Glúten milho 60 & \multicolumn{4}{|c|}{5,00} \\
\hline Farinha de aveia & \multicolumn{4}{|c|}{3,00} \\
\hline Sebo bovino & \multicolumn{4}{|c|}{5,00} \\
\hline Sal comum & \multicolumn{4}{|c|}{0,50} \\
\hline Premix vitamínico e mineral $^{1}$ & \multicolumn{4}{|c|}{0,05} \\
\hline Palatabilizante $^{2}$ & \multicolumn{4}{|c|}{1,50} \\
\hline \multicolumn{5}{|c|}{-------Composição química analisada (\% na matéria seca)------- } \\
\hline DGM $(\mu \mathrm{m})$ & 468 & 476 & 499 & 588 \\
\hline Proteína bruta & 25,0 & 25,9 & 26,8 & 27,1 \\
\hline Extrato etéreo hidrólise ácida & 6,8 & 7,1 & 6,9 & 7,4 \\
\hline Fibra bruta & 2,1 & 2,3 & 2,1 & 2,9 \\
\hline Extrativos não nitrogenados & 53,0 & 54,8 & 54,7 & 53,7 \\
\hline Energia bruta $\left(\mathrm{kcal} \mathrm{kg}^{-1}\right)$ & 3950 & 3930 & 3940 & 3950 \\
\hline
\end{tabular}

${ }^{1}$ Adição por quilograma de produto: Vitamina A - 22000UI, Vitamina D - 2200UI, Vitamina E - 90UI, Vitamina B1- 1ppm, Vitamina B2 - 7ppm, Ac pantotenico 12ppm, Niacina - 14ppm, Vitamina B6 - 1ppm, Ácido fólico - 0,2ppm, Vitamina - B12 $22 \mathrm{mcg}$, Colina - 1200ppm, Zinco - 140ppm, Ferro - 80ppm, Cobre - 7,5ppm, Iodo - 1,5ppm, Selênio - 0,2ppm.

${ }^{2}$ Fígado de aves hidrolisado.

DGM = diâmetro geométrico médio. 
ensaio de digestibilidade foi conduzido pelo método da coleta total de fezes. Foi utilizado um fator de correção para estimativa da perda energética pela urina conforme a AAFCO (2004).

A água foi fornecida ad libitum, e a alimentação foi oferecida duas vezes ao dia, as 10 e 18 horas, de acordo com o peso metabólico do animal. A quantidade fornecida por animal foi calculada com base nas necessidades de energia metabolizável diária (NEM) para atender as necessidades de mantença, segundo a equação: NEM $\left(\mathrm{kcal} \mathrm{dia}^{-1}\right)=132 \times \mathrm{PV}^{0,75}$ (NRC, 1985).

As amostragens das dietas foram realizadas diariamente nas fases de adaptação e de coleta. As fezes de cada animal foram coletadas duas vezes ao dia, durante o período de coleta, pesadas individualmente e congeladas em freezer $\left(-15^{\circ} \mathrm{C}\right)$, originando, ao final do período, uma amostra composta de cada animal. As fezes produzidas pelos cães durante o período de coleta foram avaliadas sempre pelo mesmo pesquisador, atribuindo-se pontuação de escore de 1 a 5, sendo: $1=$ fezes pastosas e sem forma; 2 = fezes macias, malformadas e que assumem o formato do recipiente de coleta; 3 = fezes macias, formadas, úmidas e que marcam o piso; 4 = fezes bem formadas, consistentes e que não aderem ao piso; $5=$ fezes bem formadas, duras e secas (SÁ-FORTES, 2005).

Ao término do experimento, as amostras compostas de fezes de cada cão foram descongeladas, homogeneizadas e secas a $55^{\circ} \mathrm{C}$, em estufa de ventilação forçada durante 72 horas. As amostras das dietas e fezes foram analisadas para determinação dos teores de matéria seca (MS), proteína bruta (PB), fibra bruta (FB) e matéria mineral (MM) de acordo com SILVA \& QUEIROZ (2002). A análise de extrato etéreo em hidrólise ácida (EEA) foi realizada segundo metodologia descrita pela AOAC (1995). A fração correspondente aos extrativos não nitrogenados (ENN) foi determinada pela fórmula: $\mathrm{ENN} \%=100$ ( $\% \mathrm{UM}+\% \mathrm{~PB}+\% \mathrm{FB}+\% \mathrm{EEA}+\% \mathrm{MM})$, sendo UM o teor de umidade da amostra (100-\%MS). A energia bruta (EB) das dietas e fezes foi determinada em bomba calorimétrica. A energia metabolizável (EM) foi estimada segundo a AAFCO (2004):
$\mathrm{EM}\left(\mathrm{kcal} \mathrm{g}^{-1}\right)=\left\{\mathrm{kcal} \mathrm{g}^{-1} \mathrm{~EB}\right.$ ingerida $-\mathrm{kcal} \mathrm{g}^{-1}$ EB das fezes $-[$ (g PB ingerida $-\mathrm{g}$ PB das fezes $) \mathrm{x} 1,25 \mathrm{kcal}$ $\left.\left.\mathrm{g}^{-1}\right]\right\} / \mathrm{g}$ ração ingerida.

Com base nos resultados laboratoriais obtidos, foram determinados os coeficientes de digestibilidade aparente (CDA) das dietas, conforme equação abaixo:

$\mathrm{CDA} \%=[($ nutriente ingerido - nutriente excretado)/ nutriente ingerido] x 100.

Os resultados dos CDA foram submetidos à análise de variância, utilizando o procedimento GLM, do programa computacional SAS (1996). Foram realizadas análises de correlação e regressão para descrever a relação dos CDA em função do DGM. Os resultados do escore fecal foram analisados pelo teste Qui-quadrado, a 5\% de probabilidade.

\section{RESULTADOS E DISCUSSÃO}

A análise de correlação (Tabela 2) demonstrou que houve relação negativa entre o DGM e os CDA da $\mathrm{PB}(\mathrm{P}<0,01)$, EEA $(\mathrm{P}<0,05)$, ENN $(\mathrm{P}<0,001)$ e metabolizabilidade da energia $(\mathrm{P}<0,001)$. Esses resultados demonstram que, com o aumento na granulometria da dieta, houve redução na digestibilidade dos nutrientes e na energia metabolizável, sendo os maiores valores de correlação observados entre o DGM e as variáveis CDA dos ENN $(-0,6039)$ e EM $(-0,6048)$. Não foi observada relação entre o consumo de matéria seca (CMS) e os CDA das dietas e EM.

Os valores de CMS, CDA e EM das dietas estão apresentados na tabela 3. Apesar de serem valores considerados satisfatórios, os coeficientes observados encontram-se abaixo dos relatados na literatura (BAZOLLI, 2007; RIVERA et al., 2007). Vários são os fatores que podem ter influenciado os valores obtidos, dentre eles, a idade dos animais utilizados, a composição química da dieta, os ingredientes e o processamento dos alimentos.

Em relação aos valores obtidos para o CDA da FB, estes apresentaram alto coeficiente de variação (Tabela 3), provavelmente devido à baixa acurácia da

Tabela 2 - Correlação entre o diâmetro geométrico médio (DGM), o consumo de matéria seca (CMS), os coeficientes de digestibilidade aparente (CDA) da matéria seca (MS), a proteína bruta (PB), o extrato etéreo ácido (EEA), os extrativos não nitrogenados (ENN) e a energia metabolizável (EM).

\begin{tabular}{lcccccc}
\hline & CMS & CDA MS & CDA PB & CDA EEA & CDA ENN \\
\hline DGM & $-0,0756$ & $-0,2058$ & $-0,4783 * *$ & $-0,3498^{*}$ & $-0,6039 * * *$ & $-0,6048^{* * *}$ \\
CMS & & 0,0336 & $-0,2342$ & $-0,2102$ & $-0,2314$ & $-0,2684$ \\
\hline
\end{tabular}

$* \mathrm{P}<0,05, * * \mathrm{P}<0,01 ; * * * \mathrm{P}<0,001$ 
Tabela 3 - Análise de regressão polinomial e médias do consumo de matéria seca (CMS, g/animal/cinco dias), coeficientes de digestibilidade aparente $(\%)$ da matéria seca (CDMS), proteína bruta (CDPB), extrato etéreo hidrólise ácida (CDEEA), fibra bruta (CDFB) e extrativos não nitrogenados $(\mathrm{CDENN})$ e energia metabolizável $\left(\mathrm{EM}, \mathrm{kcal} \mathrm{kg}^{-1}\right)$ das dietas experimentais.

\begin{tabular}{|c|c|c|c|c|c|c|c|c|c|}
\hline \multirow{2}{*}{ Variáveis } & \multicolumn{5}{|c|}{ 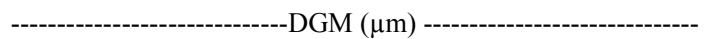 } & \multicolumn{2}{|c|}{---------P--------- } & \multirow{2}{*}{$r^{2}$} & \multirow{2}{*}{ Equação } \\
\hline & 468 & 476 & 499 & 588 & $\mathrm{CV}$ & Q & $\mathrm{L}$ & & \\
\hline CMS & 1461 & 1436 & 1462 & 1473 & 3,69 & NS & NS & 0,01 & - \\
\hline CDMS & 88,27 & 87,55 & 86,24 & 86,51 & 2,83 & NS & NS & 0,04 & - \\
\hline $\mathrm{CDPB}$ & 76,63 & 73,57 & 73,38 & 70,29 & 4,20 & NS & NS & 0,22 & $y=94,82-42,05 x$ \\
\hline CDEEA & 72,41 & 70,00 & 65,96 & 66,78 & 5,19 & $<0,01$ & NS & 0,12 & $y=86,57-35,02 x$ \\
\hline CDFB & 56,11 & 67,55 & 62,56 & 81,98 & 13,11 & $<0,01$ & NS & 0,51 & $y=-25,30+181,88 x$ \\
\hline CDENN & 80,29 & 79,28 & 77,89 & 74,14 & 4,23 & $<0,01$ & $\mathrm{NS}$ & 0,36 & $y=102,48-48,42 x$ \\
\hline EM & 2840,08 & 2769,03 & 2727,36 & 2607,15 & 3,75 & $<0,01$ & NS & 0,37 & $y=3597,56-1697,00 x$ \\
\hline
\end{tabular}

DGM - Diâmetro geométrico médio, CV - Coeficiente de variação (\%), P - Probabilidade para efeitos linear (L) e quadrático (Q), NS - Não significativo, $\mathrm{r}^{2}$ - Coeficiente de determinação.

sua técnica de determinação, o que pode ser atribuído aos baixos teores de fibra das dietas. Não foi observado efeito do DGM sobre o CMS e CDA da MS (Tabela 3). Os CDA da PB, EEA, ENN apresentaram comportamento linear com o aumento do DGM, de modo que, pela equação de regressão, verificaram-se menores CDA à medida que aumentou o DGM das dietas. Resultados semelhantes foram obtidos por BAZOLLI (2007), que relatou maiores CDA de dietas à base de milho moído em menores granulometrias, sendo os melhores resultados obtidos, pelas equações de regressão, com os DGM $475 \mu \mathrm{m}$ para MS; $350 \mu \mathrm{m}$ para os ENN; $525 \mu \mathrm{m}$ para $\mathrm{PB}$ e $444 \mu \mathrm{m}$ para o EEA.

Como o grau de gelatinização do amido é inversamente proporcional ao tamanho do grão, já que partículas menores apresentam maior superfície de exposição à temperatura, isso provavelmente explica o fato do aumento da digestibilidade com menores granulometrias. Por outro lado, o menor tamanho de partículas resulta em aumento na taxa de passagem do alimento pelo trato digestório, reduzindo o tempo de ação das enzimas digestivas sobre os nutrientes e sua absorção, o que pode comprometer o aproveitamento dos nutrientes pelo organismo.

O milho foi a principal fonte de amido utilizada na formulação das dietas experimentais (Tabela 1) e este pode ser um fato relevante, pois, segundo BAZOLLI (2007), o efeito da granulometria sobre a digestibilidade é dependente do ingrediente utilizado, uma vez que em seu trabalho a redução de partículas não resultou em aumento de digestibilidade dos nutrientes nas dietas contendo arroz. Esse efeito foi obtido apenas quando as fontes de amido utilizadas foram o milho e o sorgo.
A equação gerada para a digestibilidade da FB, embora tenha sido linear e significativa, não possibilita a explicação do seu comportamento, possivelmente por problemas na determinação laboratorial do teor de FB, como explicado anteriormente.

Os resultados obtidos demonstram que ingredientes grosseiramente moídos podem reduzir o aproveitamento dos nutrientes da dieta pelos animais, acarretando prejuízo a sua manutenção, ao seu crescimento e ao seu desenvolvimento. A EM declinou com o maior DGM, apresentando variação de 2840 a $2607 \mathrm{kcal} \mathrm{kg}^{-1}$ de EM para os DGMs 468 e $588 \mu \mathrm{m}$, respectivamente (Tabela 3). Observa-se, dessa forma, que a redução do tamanho das partículas aumentou de forma linear a eficiência de utilização da energia presente nos alimentos pelos animais. Esse resultado está de acordo com o observado por WONDRA et al. (1995), em estudo realizado com suínos, e por OPALINSKI (2006), trabalhando com aves, os quais relatam aumento nos valores de EM em animais recebendo dietas com menor tamanho de partículas.

Outro importante aspecto na nutrição de cães é a avaliação da qualidade das fezes produzidas, uma vez que os proprietários dos animais priorizam alimentos que possibilitam fezes de consistência adequada, de forma a facilitar a higienização do ambiente nos quais os animais são criados. A avaliação do escore das fezes revelou que o aumento da granulometria para DGM $588 \mu \mathrm{m}$ resultou em menor escore fecal $(3,28)$, tornando as fezes mais líquidas. No entanto, cães alimentados com as dietas com DGMs de 468, 476 e $499 \mu \mathrm{m}$ apresentaram escores médios de 3,$97 ; 3,92$ e 3,80, respectivamente, não diferindo entre

Ciência Rural, v.39, n.8, nov, 2009. 
si. O menor escore fecal em cães alimentados com dietas com maior DGM das partículas também foi observado por BAZOLLI(2007).

O grau de moagem dos ingredientes é uma variável importante a ser considerada no processo industrial, visto que, apesar de a menor granulometria da dieta melhorar a digestibilidade dos nutrientes, há maior gasto de energia e menor eficiência do processo produtivo na fábrica. Sendo assim, são necessários mais estudos sobre dietas com diferentes granulometrias para cães, principalmente quanto à avaliação de diferentes ingredientes, à taxa de passagem, à qualidade do extrusado e ao ponto ótimo entre digestibilidade e eficiência produtiva na fábrica de ração.

\section{CONCLUSÕES}

Moagens mais finas dos ingredientes de alimentos extrusados resultam em melhor aproveitamento dos nutrientes, maior eficiência da utilização de energia e melhor qualidade das fezes nos cães.

\section{REFERÊNCIAS}

AAFCO (Association of American Feed Control Officials) Oxford, 2004. 276p. (Official Publication).

ANFALPET (Associação Nacional dos Fabricantes de Alimentos para Animais de Estimação). Piq Pet. Manual do Programa Integrado de Qualidade Pet. São Paulo, 2008. 238p.

AOAC (Association of the Official Analytical Chemists) Official and tentative methods of analysis. 16.ed. Arlington, 1995. 2000p.

BAZOLLI, R.S. Influência do grau de moagem de ingredientes amiláceos utilizados em rações extrusadas sobre os aspectos digestivos e respostas metabólicas em cães. 2007. 82f. Tese (Doutorado em Medicina Veterinária Clínica Médica) - Universidade Estadual Paulista, Jaboicabal, SP.

CARCIOFI, A.C. et al. Avaliação de dietas com diferentes fontes protéicas para cães adultos. Revista Brasileira de Zootecnia, v.35, n.3, p.754-760, 2006. Disponível em: <http://www.scielo.br/ scielo.php? script=s ci arttext\&pid=S 1516 35982006000300017>. Acesso em: 22 mai. 2007. doi: 10.1590/ S1516-35982006000300017.

DAHLKE, F. et al. Tamanho da partícula do milho e forma física da ração e seus efeitos sobre o desempenho e rendimento de carcaça de frangos de corte. Revista Brasileira de Ciência Avícola, v.3, n.3, p.211-217, 2001

HAMILTON, R.M.G.; PROUDFOOT, F.G. Ingredient particle size and feed texture: effects on the performance of broiler chickens. Animal Feed Science Technology. v.51, p.203210,1995

HEALY, B.J. et al. Optimum particle size of corn and hard and soft sorghum for nursery pigs. Journal of Animal Science, v.72, p.2227-2236, 1994

NACIONAL RESEARCH COUNCIL. Nutrient requirements of dogs. Washington: National Academy, 1985. 79p

OPALINSKI, M. Utilização de enzima e soja integral em rações para frangos formuladas com ingredientes alternativos com base em aminoácidos digestíveis e totais. 2006. 118f Dissertação (Mestre em Ciências Veterinárias ) - Universidade Federal do Paraná, Curitiba, PR.

RIVERA, N.L.M. et al. Digestibility of nutrients with the inclusion of conjugated linoleic acid in the diet of dogs. Archives of Veterinary Science, v.12, p.52-57, 2007.

SÁ-FORTES, C.M.L. Valor nutricional de ingredientes energéticos e protéicos para cães. 2005. 82f. Tese (Doutorado em Zootecnia) - Universidade Estadual Paulista, Jaboticabal, SP.

SAS Statistical Analysis System: users guide. Cary, NC, 1996. 584p.

SILVA, D.J.; QUEIROZ, A.C. Análise de alimentos: métodos químicos e biológicos. Viçosa, MG: UFV, 2002. 235p.

WONDRA, K.J. et al. Effects of reducing paricle size of corn in lactation diets on energy and nitrogen metabolism in secondparity sows. Journal of Animal Science, v.73, p.427-432, 1995.

ZANOTTO, D.L; BELlAVER, C. Método de determinação da granulometria de ingredientes para uso em rações em suíno e aves. Concórdia, SC: EMBRAPA-CNPSA, 1996. 5p. (Comunicado Técnico, 215). 